\title{
Inclusión sociolaboral: inmigrantes internacionales y mujeres en puestos de inserción en Euskadi ${ }^{1}$
}

\section{María Esther Aretxabala}

FLACSO-España

<esther.aretxabala@gmail.com>

\section{María Luisa Setién}

Universidad de Deusto

\begin{abstract}
Artikulu honetan nabarmendu nahi da ekonomia sozial eta solidarioaren agente aktibo diren gizarteratzeko enpresen garrantzia eta berauen bidez eskaintzen diren konponbideak, betiere, atzerriko jatorria duten langileak lan-munduan txertatzeko arloan; eta horretarako erabili da 2011 eta 2012. urtean diziplina desberdinetan oinarritutako ikerketa bat. Enpresa sozial horiek bideratutako esperientziak oso garrantzitsu gertatzen dira ahultasun sozialean dauden lagunen gizarteratze eta lan txertaketarako gero eta pluralagoa, hautsiagoa eta logika inklusiboa premiako duen testuinguru batean.
\end{abstract}

\section{GAKO-HITZAK:}

Gizarteratzeko enplegua, ekonomia sozial eta solidarioa, Euskal Autonomia Erkidegoa, lan txertaketa, integrazio soziala, kaltetutako kolektiboak.
Este artículo pretende poner de relieve el peso y las soluciones implementadas por uno de los agentes activos de la economía social y solidaria vasca, las empresas de inserción, de cara a la integración sociolaboral de sus trabajadoras y de sus trabajadores de origen extranjero en puestos de inserción, a partir de los resultados de una investigación multidisciplinar llevada a cabo durante 2011 y 2012. Las experiencias que estas empresas sociales implementan representan un elemento clave de actuación que ayuda a la inclusión sociolaboral de las personas en situación de fragilidad social en un contexto cada vez más plural y fracturado, que exige una nueva lógica inclusiva.

\section{Palabras clave:}

Empleo de inserción, economía social y solidaria, Comunidad Autónoma del País Vasco, inclusión laboral, integración social, colectivos desfavorecidos. 


\section{Introducción: contexto y metodología}

Hace dos décadas era difícil imaginar el intenso proceso de transformación social de la Comunidad Autónoma del País Vasco (CAPV), que ha desembocado en un nuevo modelo de sociedad, más plural y fracturado. La dimensión de pluralidad de tal modelo obedece principalmente al voluminoso contingente de población nacida en el extranjero residente en territorio vasco, que en 2015 supone 183.891 vecinos y representa el $8,4 \%$ del total de la población vasca (Ikuspegi, 2015), y cuyo asentamiento no ha representado importantes grados de crispación. Por su parte, la fractura en este nuevo modelo social es fruto de la diferenciación surgida de la gran destrucción del tejido productivo y de puestos en el mercado laboral, así como del empeoramiento de las condiciones de la función protectora social del Estado de bienestar por los ajustes y recortes económicos implantados desde 2008, que han incidido en el repliegue de las prestaciones públicas y de los servicios sociales. El pujante incremento de las tasas de marginación y la falta de oportunidades son fuentes potenciales de conflictividad, en un clima social marcado por el desasosiego, con problemas tremendos a los que se debe enfrentar una buena parte de la ciudadanía menos favorecida. En este nuevo escenario, como refleja un informe de Cáritas Española (2013), aumentan las desigualdades sociales, la pobreza y los procesos de exclusión social ${ }^{2}$, especialmente entre grupos sociales como las mujeres o los inmigrantes internacionales, que partían de situaciones más desfavorables (Rocha y Aragón, 2012).

Esta compleja tesitura nos deriva hacia el mercado laboral, ya que el empleo sigue siendo el mejor medio de inclusión social. Determinados factores referidos a las dificultades de los propios sujetos que se encuentran en situación de precariedad y vulnerabilidad -falta de formación y experiencia, menores habilidades sociales, baja autoestima- hacen que ciertos colectivos sufran un mayor riesgo de exclusión social y de dificultad para acceder al mundo laboral normalizado. A estos grupos de personas se los denomina colectivos vulnerables. Como señala Cruz Roja en el caso concreto de España, su situación laboral evidencia que existe una "fuerte segregación laboral y horizontal vinculada tanto al género como a la nacionalidad de los trabajadores y trabajadoras" (2011: 75). La población de origen extranjero muestra, en particular, porcentajes de desempleo aún mayores que los de la población en general ${ }^{3}$ y cifras más

${ }^{2}$ Según datos de 2012, en la CAPV se ha incrementado un $48 \%$ el número de personas afectadas por la pobreza real respecto a 2008 , y las que se encuentran en riesgo de pobreza han aumentado más de 3 puntos, del 4,1\% en 2008 al 7,3\% registrado en 2012 (Gobierno Vasco, 2012a). Además, se da la circunstancia de que España es el país de la zona euro donde el riesgo de pobreza o exclusión social más ha aumentado entre 2009 y 2010 , habiendo alcanzado al 25,5\% de la población, lo que supone una cifra de 11,6 millones de personas (Eurostat, 2012).

${ }^{3}$ La tasa de paro de las personas de origen inmigrante se ha triplicado desde finales de 2007 , cuando se situaba en torno al $12 \%$, pasando a rondar el $36 \%$ a mediados de 2013 (INE, 2013). Concretamente en la CAPV, la tasa de pobreza de mantenimiento es casi siete altas de paro de larga duración; y sin empleo, estas personas pierden el permiso de residencia, lo cual les supone una irregularidad sobrevenida, extensible a sus descendientes (Arango, 2012). La combinación de la falta de empleo y el aumento de recortes conlleva un incremento considerable de la marginalidad y de la caída hacia las bolsas de exclusión para los inmigrantes internacionales que carecen del 'colchón' socioeconómico con el que habitualmente cuentan los nativos. Tal combinación de factores estructurales ha acarreado el deterioro de las condiciones de vida para muchas personas de origen extranjero -paro, depauperación, embargos-, erosionando los fundamentos de su integración (Laparra y Pérez Eransus, 2012).

Por otro lado, las diferencias biológicas del sexo se han estructurado en jerarquías y distinciones sociales entre hombres y mujeres, siendo estas últimas quienes han padecido de manera más negativa las consecuencias de tal desigualdad (dificultades de acceso al mercado laboral, reparto de tareas, menores retribuciones por un mismo trabajo). De ahí que las mujeres, por su condición, sufran ciertas discriminaciones y desigualdades, y si a ello además se aúnan otra serie de problemas personales y sociales, se pueden vislumbrar mujeres en situación de desventaja con dificultades para desarrollar una vida normal, digna y plena. Asimismo, la participación laboral de las mujeres presenta una mayor vulnerabilidad debido a una serie de desequilibrios estructurales del mercado de trabajo con efectos negativos, tales como menores tasas de empleo, segregación sectorial y ocupacional, mayor presencia de contratos atípicos, y niveles salariales inferiores (Rocha y Aragón, 2012). Por tanto, procurar la integración y promoción social de las mujeres es una tarea capital para el desarrollo del territorio vasco ${ }^{4}$.

Consiguientemente, la situación para acceder al mercado de trabajo -gran factor de normalización e integración- de los grupos en desventaja apela a considerar elementos de innovación social e inclusión activa. Es ahí donde la economía social y solidaria entra en juego, dado que representa un sector más receptivo a la incorporación de ciertos grupos sociales más vulnerables. Este sector de la economía, donde se incluyen las empresas de inserción, ha comenzado a dar respuestas específicas, siendo pionero en la búsqueda de mecanismos de integración con personas desfavorecidas, inmigrantes y mujeres entre ellas, al ofrecer alternativas novedosas desde una filosofía enmarcada en ciertos principios fundamentales que armonizan valor económico con valores sociales.

veces más elevada en los hogares de personas extranjeras (34\%) que en los de nacionales ( $5 \%$ ), y se ha incrementado en cuatro puntos desde 2008 (Gobierno Vasco, 2012a).

${ }^{4}$ Como se concluye en el III Plan Vasco de Inclusión Activa 2012. 2016 (Gobierno Vasco, 2012b: 18), el rostro de la pobreza es femenino: son mujeres más de dos tercios de las personas perceptoras de renta básica; la población femenina no sólo es dominante entre los colectivos más pobres ( $53 \%$ ), sino también, en general, entre quienes experimentan ausencia de bienestar (57\%). 
Ante este panorama, nos surgían una serie de preguntas que guiaron una investigación multidisciplinar desarrollada durante 2011 y 2012, a saber, ¿cuál es el papel de la economía social y solidaria, en concreto de las empresas de inserción, como elemento valedor en el mercado de trabajo vasco, en la empleabilidad de las mujeres y de la población de origen inmigrante en desventaja?; ¿cuál es el peso de los inmigrantes y de las féminas vulnerables empleados en las empresas de inserción?; ¿a través de qué procesos de inserción se consigue la integración de estas personas en este tipo de empresas sociales? Tratamos de responder estas cuestiones analizando los colectivos de inmigrantes internacionales y de mujeres en puestos de inserción en la CAPV, desde una metodología de análisis mixta, con técnicas cualitativas, gracias a más de un centenar de entrevistas en profundidad tanto a mandos responsables de las empresas de inserción y de sus entidades promotoras como a los propios trabajadores en inserción; así como con instrumentos cuantitativos, merced a cuatro cuestionarios cerrados para todas las empresas de inserción vascas miembros de Gizatea -la asociación que las agrupa en la CAPV- con empleados de origen extranjero y mujeres, y para los propios inmigrantes y mujeres empleados en inserción.

La primordial aportación de este artículo se centra en poner de manifiesto la relevancia social de tales agentes de la economía social y solidaria vasca, y en reflexionar sobre tal realidad desde el prisma de la incorporación sociolaboral del capital humano femenino e inmigrante, a través de las empresas de inserción vascas. Con ello, se tratará de abordar los mecanismos utilizados para afrontar de forma óptima los nuevos retos que surgen en el dinámico sistema social vasco, donde aún están por instituir medidas para la resolución idónea de los cambios vividos recientemente, cambios que han derivado en el modelo social plural y fracturado al que aludíamos en líneas anteriores. Es decir, en el marco de una sociedad desarrollada y organizada sobre parámetros democráticos como la vasca, nuestro interés es reconocer y visualizar el alcance real que tiene el empleo de inserción específico entre colectivos vulnerables como pueden ser ciertos perfiles de mujeres y de inmigrantes internacionales.

Para ello, en un primer apartado nos referiremos al empleo de inserción dentro del panorama vasco de la economía social y solidaria. En una segunda sección, plasmaremos la fotografía que suponen las mujeres y las personas de origen extranjero empleados de inserción en las empresas de inserción vascas. Para terminar, se señalan las principales consideraciones del análisis realizado para el conjunto de agentes sociales.

\section{Economía social y solidaria, marco para el empleo de inserción en la CAPV}

La economía social y solidaria resulta un sector decisivo con un gran potencial, al constituirse en una de las vías más coherentes y directas para contribuir a la sostenibilidad de los derechos sociales. Este tipo de economía siempre se ha caracterizado por dar respuestas innovadoras a las necesidades sociales que no encuentran una solución adecuada por parte de los agentes económicos tradicionales, sean públicos o privados (Marcuello et al., 2008), y representa el beneficio común, la cooperación y la no competencia en ámbitos donde se retiran tanto el Estado como el mercado tradicional. Así, supone una esfera económica capaz de articular propuestas que anteponen las personas al capital y, como un área de participación social a través de la actividad económica, ofrece soluciones concretas y modelos eficientes (Figura 1).

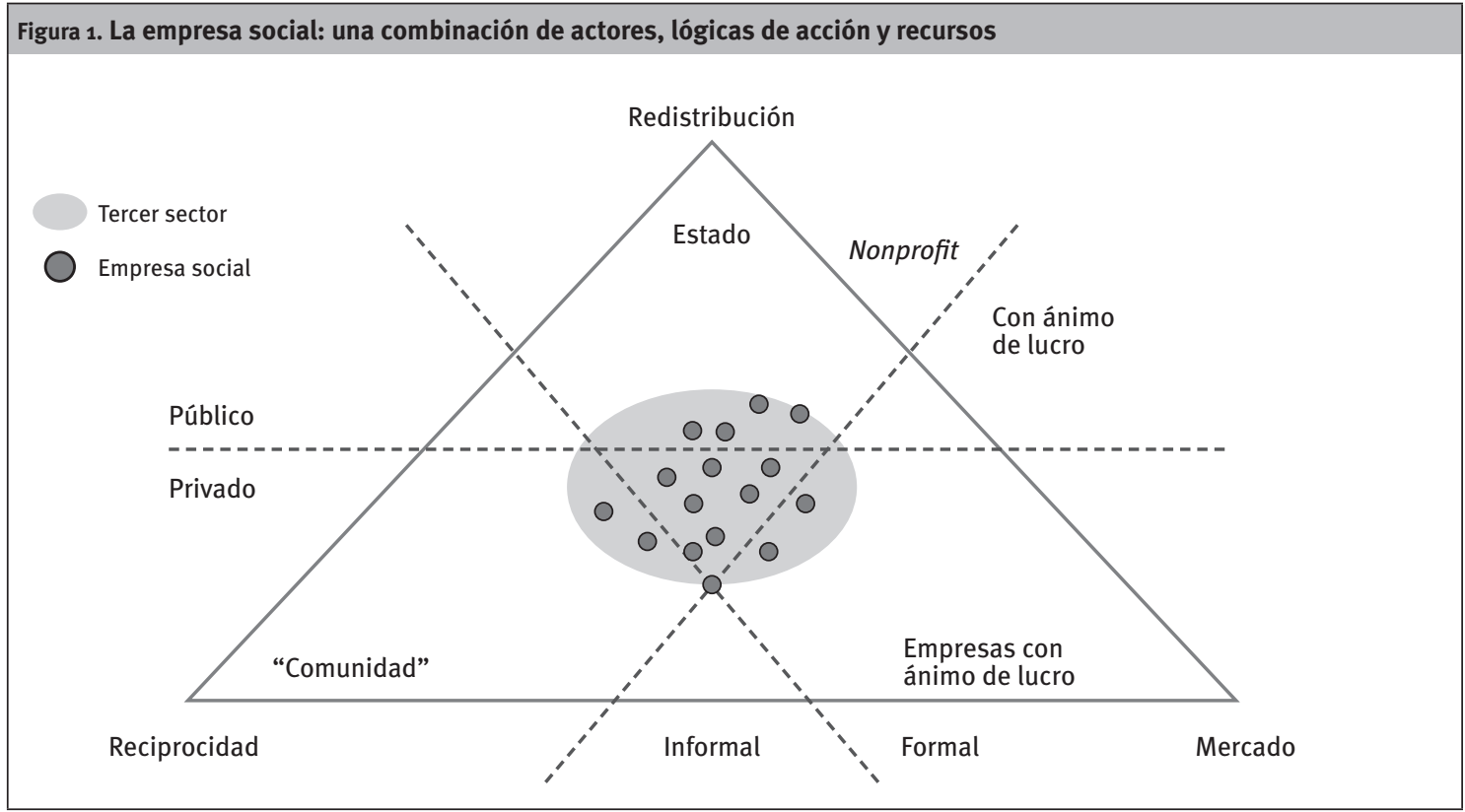

Fuente: Defourny y Nyssens (2013), basándose en Pestoff (1998 y 2005). 
Su papel es fundamental, al dar especial importancia al empleo femenino, al hacer aflorar empleo de la economía sumergida, al amortiguar los procesos de reconversión industrial y al integrar a los colectivos más vulnerables, empoderándolos pese a su difícil empleabilidad (Urra, 2010). Por ello, la economía social y solidaria se imbrica estrechamente con el apoyo a la inserción sociolaboral, al ser un ámbito que genera una actividad económica palpable y que produce rendimientos no solamente económicos, también de inserción social, como elemento novedoso en el campo de la acción social. En la CAPV, durante 2013 se agrupaban en este sector de la economía social más de 70.600 trabajadores, que representaban algo más del $8 \%$ del empleo, y estaba integrado por 2.357 empresas, el 1,26\% del total de entidades existentes (Observatorio Vasco de Economía Social, 2014).

Como señala la Carta de la Economía Solidaria (REASEuskadi, 2011), la economía solidaria pretende, dentro del marco de la tradición de la economía social5, incorporar a la gestión de la actividad económica los valores universales que deben regir la sociedad y las relaciones entre toda la ciudadanía: equidad, justicia, fraternidad económica, solidaridad social y democracia directa. Las entidades de la economía social y solidaria generan empleo y riqueza, logrando mayores niveles de cohesión y bienestar social, al complementar y llegar donde no lo hacen ni el sector público ni el mercado. En definitiva, la economía social y solidaria contribuye de manera clara a un desarrollo social y económico más equilibrado, equitativo y solidario, favoreciendo la cohesión social, el progreso local y territorial y la innovación.

Las empresas de inserción ${ }^{6}$, como actores del abanico de entidades de la economía social y solidaria, son instrumentos impulsados por organizaciones no lucrativas ${ }^{7}$, como asociaciones sin fines lucrativos o fundaciones, que aseguran la prestación de medidas

${ }_{5}$ La Ley estatal 5/2011 de Economía Social define ésta como el conjunto de las actividades económicas y empresariales que, en el ámbito privado, llevan a cabo aquellas entidades que persiguen bien el interés colectivo de sus integrantes, bien el interés general económico o social, o ambos. Integra a cuatro grandes familias de entidades, cooperativas, mutualidades, fundaciones y asociaciones que lleven a cabo actividad económica, y también incluye a las sociedades laborales, las empresas de inserción, los centros especiales de empleo, las cofradías de pescadores, las sociedades agrarias de transformación y las entidades singulares creadas por normas específicas que se rijan por los principios establecidos en esta novedosa ley.

${ }^{6}$ Desde $\mathbf{2 0 0 7}$, cuentan con la Ley 44/2007, de Empresas de Inserción. También a escala estatal, disponen de la siguiente normativa: la Ley 27/2009, de Medidas Urgentes para el Mantenimiento y el Fomento del Empleo y la Protección de las Personas Desempleadas; y el Real Decreto 49/2010, de 22 de enero, por el que se crea el Registro Administrativo de Empresas de Inserción del Ministerio de Trabajo e Inmigración, que supone un desarrollo de la ley vigente.

7 Estos promotores participan como mínimo en un $51 \%$ de su capital, y en el caso de las sociedades cooperativas y sociedades laborales, dicha participación debe situarse en los límites máximos recogidos en las diferentes legislaciones (Gizatea, 2010). Las empresas de inserción son dispositivos empresariales que deben aplicar los excedentes obtenidos en cada ejercicio (hasta el $80 \%$, según la ley estatal) a la mejora o ampliación de sus estructuras productivas o a la promoción de actividades relacionadas con la inserción sociolaboral, no debiendo producir, en ningún caso, reparto de beneficios. de acompañamiento social y desarrollan programas de incorporación sociolaboral para la asunción de competencias, habilidades y responsabilidades a las personas en proceso de inserción en un entorno empresarial, como trampolín para dar el salto al mercado laboral ordinario mediante una gestión integral del fenómeno multicausal de la vulnerabilidad social (Aretxabala, 2012).

Como señalan María Elena Gil y Nieves Ramos (2013), las empresas de inserción son un modelo de economía social de eficacia reconocida para la inserción sociolaboral de personas con dificultades de acceso al mercado laboral, siendo un importante mecanismo para la puesta en práctica de las políticas activas de empleo, por su propio modelo de gestión. Estas empresas con diferentes formas jurídicas (sociedades limitadas, laborales, cooperativas), de manera autónoma y económicamente viable producen bienes y servicios, y ofrecen itinerarios personalizados de formación, empleo e inserción sociolaboral a personas en riesgo o situación de exclusión social. La metodología de estos mecanismos productivos para sus empleados en inserción complementa un itinerario personalizado estructurado en torno a tres ejes -el personal, el técnico-profesional y el sociolaboral-, que pretende acompañar a la persona en inserción con formación práctica, en un ambiente laboral real y en sucesivas fases. En palabras de uno de los promotores de las empresas de inserción vascas:

Nos suelen decir que cuando ningún recurso sirve en otro entorno, aquí suele encajar. Por el tipo de trabajo que hacemos, por cómo lo hacemos, por cómo hacemos los procesos, por cómo acompañamos a las personas... En cuanto al proceso de inserción, es un poco tipo. En primer lugar, hay una acogida. Hay dos personas que se dedican a recibir a la gente que viene, se escucha qué es lo que demandan y se les cuenta qué es lo que podemos ofrecerles... En [la fase de] diagnóstico, se intenta definir muy bien qué es lo que esa persona quiere, qué sector le gusta. Se acompaña a que definan bien la demanda, intentas que el diagnóstico sea lo más ajustado posible a la realidad de la persona. Cuando ya hay un diagnóstico realizado, se hace una propuesta... Siempre hay algo que se tiene en cuenta, esté en el paso en el que esté, y es un itinerario para cada persona. Se elabora un itinerario para cada persona de inserción, donde entran tres componentes: uno que tiene que ver con lo técnico-profesional, qué oficio va a aprender, qué necesitas y qué habilidades tienes que incorporar de esa tarea; otro que tiene que ver con lo sociolaboral, son cosas que todos tenemos que conocer de lo que es el mundo del trabajo, qué es un convenio laboral, cómo negocio; y luego hay otra parte que es la socioeducativa, que es lo que necesita cada persona a título personal, por sus características, para que todo lo otro se mantenga. Entonces siempre trabajamos con objetivos concretos que se fijan siempre con la persona. A la persona se le propone un itinerario, y si está de acuerdo sobre eso, se avanza. Vas 
construyendo un itinerario que la persona en todo momento puede ir valorando, con el acompañamiento de un educador. El itinerario se hace a tres bandas: entre el educador, el maestro de taller y la persona $\left(\right.$ EP-02) ${ }^{8}$.

Los empleados en puestos de inserción suelen ser personas con un nivel de empleabilidad básico. En este sentido, el Decreto 182/2008, que regula la calificación de las empresas de inserción, especifica que se considerarán personas susceptibles de incorporarse a ellas con objeto de iniciar un proceso de inclusión sociolaboral a aquellas "personas en situación de exclusión social desempleadas e inscritas en los servicios públicos de empleo y que hayan suscrito un convenio de inserción”. Es decir, la situación de exclusión de las personas pertenecientes a estos colectivos deberá ser acreditada por los servicios sociales públicos competentes. De hecho, las empresas de inserción actúan como empresas de tránsito, donde personas con dificultades de inserción sociolaboral desarrollan las capacidades necesarias (empleabilidad) para el desempeño de un trabajo, mediante la fórmula de "aprender trabajando" (Salinas y Herránz de la Casa, 2004). Representan un modelo económico alternativo y eficiente que reivindica que el mercado no responde únicamente a la lógica capitalista de exclusión (Coque y Pérez Fernández, 2000; Marcuello et al., 2008), articulándose en torno a dos coordenadas fundamentales, a saber, su objeto social y el proceso sociolaboral que implantan para sus trabajadores en inserción.
Para cumplir su principal objetivo social, las empresas de inserción ofrecen a las personas en riesgo de exclusión social un contrato de trabajo de un mínimo de 6 y un máximo de 36 meses de duración, al amparo del convenio colectivo propio del sector en el que se encuadra la empresa, junto con un acompañamiento personalizado que incluye actuaciones de apoyo, seguimiento y formación, realizado por personal especializado que facilita la adquisición de hábitos sociales y de trabajo necesarios para la inclusión en el mercado normalizado, porque mejoran la empleabilidad de las personas participantes en ellas (Figura 2). A los sujetos en puestos de inserción, las empresas les plantean un itinerario de acompañamiento individualizado de aprendizaje adecuado, que contempla la consecución de habilidades sociales y laborales, formación básica, cualificación profesional y conocimientos de mercado, que les permiten mejorar sus condiciones de empleabilidad (Córdoba y Martínez Morales, 2011). Consiguen el compromiso de las propias personas como protagonistas de su propio desarrollo y evolución, combinando el refuerzo de la autoestima, formación e intervención educativa, implicando a cada trabajador en inserción.

Para las personas en situación o riesgo de exclusión social, las empresas de inserción representan un factor clave para lograr su integración sociolaboral, porque partiendo de una situación de desempleo y habiendo suscrito con los servicios sociales de base correspondientes un convenio de inserción como reflejo de su situación de desventaja social, cuentan

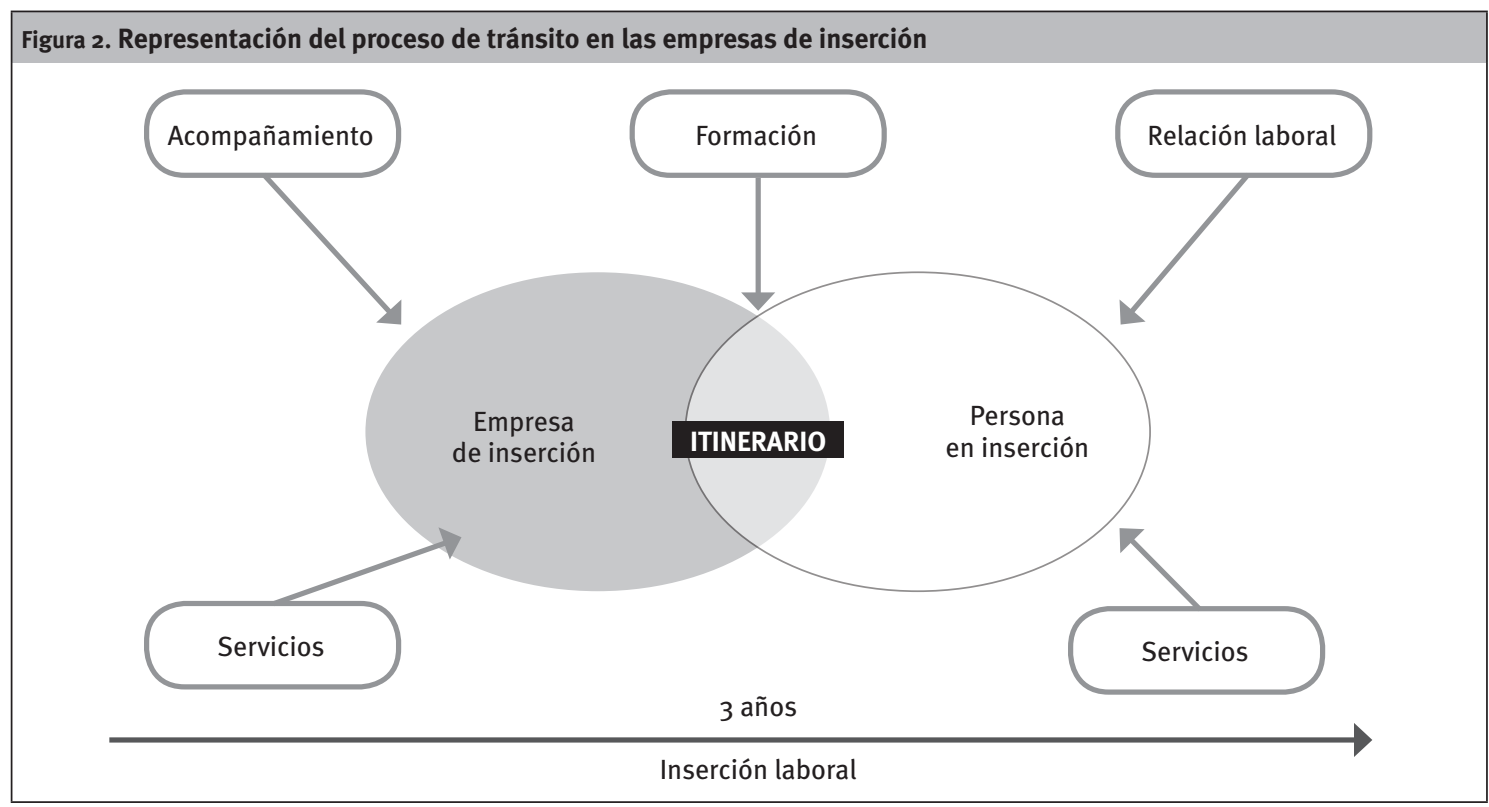

Fuente: Gil y Ramos (2013: 50).

${ }^{8}$ La nomenclatura utilizada en la referencia a las entrevistas semiestructuradas en profundidad realizadas durante el proyecto de investigación fue la siguiente: ER, responsable de redes asociativas de las empresas de inserción y de la economía social y solidaria vasca ( 3 en total); EP, responsable promotor de empresa de inserción (16 en total); GE, gerentes de empresas de inserción ( 9 en total); TA, técnicos de acompañamiento (17 en total); El, persona de origen extranjero (40 en total); y EM, mujer en plantilla de inserción (28 en total). 
con un contrato de trabajo en un entorno donde se les apoya no solamente en el desarrollo de un trabajo real, sino también en un itinerario personalizado para la asunción de destrezas y competencias personales. Conviene señalar que el nivel de productividad de las personas con este tipo de contratos de inserción es más reducido que el de un trabajador normalizado y, por esta razón, las empresas de inserción pueden optar a ciertas ayudas públicas destinadas tanto a su creación como a su mantenimiento, que se enmarcan dentro de las políticas activas de empleo. Como señala en una entrevista uno de los mandos de las empresas de inserción:

[...] hay que diferenciar cuál es el concepto de empresas de inserción que barajamos. Para nosotros es mucho más amplio, es decir, una empresa de inserción es una empresa que tiene por finalidad la creación de puestos de trabajo para poder insertar o ayudar en su trayectoria de inserción a personas con problemas de exclusión (EP-14).

Por ende, las empresas de inserción que actúan en la CAPV se fundamentan en la iniciativa social y constituyen en estos momentos un sustancial andamiaje de apoyo para todas las personas que atraviesan por dificultades, al trabajar por su inserción sociolaboral. Este hecho es la principal innovación de las empresas de inserción, que suponen iniciativas empresariales que forjan sinergias en la sociedad, ayudando a la integración de colectivos vulnerables, pero generando un impacto en el ámbito económico al mismo tiempo. Por ello, exceden las pautas del modelo económico clásico, al tener la voluntad de preparar a las personas en desventaja social en su capacitación hacia el mercado laboral ordinario, puesto que en su $A D N$ se encuentra el ser una herramienta transitoria para lograr la inclusión sociolaboral normalizada de sus trabajadores en puestos de inserción (Veciana, 2007). Los beneficiarios de este tipo de empleos dejan, por consiguiente, de ser personas pasivas y dependientes de los sistemas de protección sociales. Las empresas de inserción, en consecuencia, suponen el desarrollo de actuaciones eficaces concretas que favorecen a los colectivos más vulnerables, contribuyendo a rescatar de la exclusión social a grupos de ciudadanos marginados y facilitando su tránsito al empleo ordinario (Marcuello et al., 2008).

Por otra parte, una de las obligaciones de las empresas de inserción es mantener, desde su calificación como tales, un porcentaje anual de personas trabajadoras en procesos de inserción de al menos el $40 \%$ respecto al total de la plantilla durante los primeros tres años de actividad y, como mínimo, del $50 \%$ del total de la plantilla a partir del cuarto año, con un tope del $75 \%$ de los puestos, no pudiendo ser el número de aquellas inferior a dos. Es decir, dentro de las empresas de inserción se deben distinguir dos grandes grupos en lo que respecta a sus plantillas: por un lado, estarían los empleados, como en cualquier tipo de empresa; por otro, los empleados en puestos de inserción, pertenecientes a colectivos vulnerables.
Terminamos este apartado señalando que, en la última década, se viene observando un incremento notable de la cantidad y pluralidad de las empresas de inserción en la CAPV, estimulado por dos circunstancias paralelas y diferenciadas. Por una parte, $y$ debido a las mayores tasas de desempleo, el aumento de la demanda, la pobreza, la exclusión social o el riesgo de estarlo, con su repercusión en los colectivos más desfavorecidos, con difícil nivel de empleabilidad. Por otra parte, la apuesta decidida por la inclusión activa y el empleo, y la formación como motor de integración por parte del Gobierno Vasco y de algunos agentes sociales y económicos, para demostrar que todas las personas tienen un cierto margen para mejorar su empleabilidad, y que la orientación laboral puede ser decisiva para superar situaciones personales muy complicadas. A diferencia de las ayudas sociales, cuyo coste no tiene retornos apreciables para la economía, la economía social y solidaria, y en concreto, las empresas de inserción producen resultados en términos de generación de empleo, aumento de la capacidad de consumo, dinamismo económico o retornos a la hacienda pública a través de impuestos. En la CAPV, la devolución económica total de las empresas de inserción vascas a las administraciones públicas en 2011 se estimó en 3.346.555 euros y el retorno por plaza de inserción fue de 7.054 euros (Gizatea, 2012). Sin embargo, las empresas de inserción se han enfrentado en los últimos años a una reducción en su volumen de negocio, a problemas de liquidez, a un importante aumento de la solicitudes de acceso a las plazas en inserción y, fundamentalmente, a la disminución de las oportunidades de colocación en el mercado de trabajo ordinario para quienes terminan su proceso de inserción. Por lo tanto, se debe considerar el notable esfuerzo que, para seguir funcionando y para perfeccionar y ajustar sus procesos de gestión durante la dinámica de crisis, están realizando estas empresas productivas y las entidades que las promueven (Gizatea, 2013b).

\section{Empleo de inserción en Euskadi: inmigrantes internacionales y mujeres}

Como acabamos de señalar, el empleo de inserción -con sus peculiaridades específicas, por el acompañamiento que requiere- se enmarca en el sector de la economía social y solidaria dentro de la CAPV. Un responsable de una de las gerencias en una de las empresas de inserción vascas describe, durante la entrevista mantenida, las especificidades de los empleos de inserción:

La diferencia básica es que los contratos en inserción son contratos subvencionados. Normalmente, cuando a ti te hablan de contratos en inserción dices: "¡ah, qué bien, contratos subvencionados, fenomenal, todo fantástico!”. Tienes que pagar un tercio de lo que normalmente pagarías en seguros sociales. Realmente, la gente no se da cuenta [de] que un contrato de inserción es un contrato más caro que un contrato normalizado. [...] Entonces, hay una gente que viene con 
problemas; no sólo de adicción, aquí hay muchos problemas, hay gente con problemas de maltrato, de adicción, exreclusos. Gente que necesita un apoyo para insertarse, para llegar a una normalidad. Puede parecer que, al ser contratos subvencionados, es algo muy cómodo (GE-05).

En el empleo de inserción tiene cabida un perfil de personas con diversos problemas que necesitan de un mayor apoyo para normalizarse, de ahí que sean puestos subvencionados parcialmente. El conjunto de empleados en inserción en Euskadi ha ido variando, como se observa en el discurso de uno de los promotores de este tipo de empresas sociales:

No es una foto estática, es más bien como un vídeo. Esto está cambiando en el tiempo (14-EP-8).

Si nos fijamos, en concreto, en el conjunto de personas de origen extranjero, una gran mayoría ( $86 \%$ ) de las 44 empresas de inserción vascas miembros de la asociación Gizatea contaban en 2012 con inmigrantes internacionales en sus plantillas, que alcanzaban un volumen de 270 empleados, prácticamente en su totalidad en puestos de inserción. Dado que eran 641 los trabajadores en inserción en la CAPV, los inmigrantes internacionales superaban ligeramente el $42 \%$ del conjunto en 2012. Esta cifra resulta claramente superior al $5 \%$ que suponían los trabajadores de origen extranjero a principios de este siglo en las plantillas de estos dispositivos empresariales. Esto puede ser reflejo, a su vez, y en parte, del crecimiento del volumen de población de origen extranjero presente en la propia sociedad vasca. Además, el incremento de los inmigrantes internacionales en los puestos de inserción viene marcado por la propia idiosincrasia de este colectivo, muy afectado por los efectos negativos de la crisis desde 2008 y que ve en el trabajo el principal pilar para progresar en la sociedad donde han decidido residir, suponiendo las empresas de inserción una de las herramientas que se les ofrece a estas personas extranjeras de origen para desarrollar sus capacidades y conseguir realizar una actividad productiva, a la vez que se les presta apoyo laboral, personal y formativo. Todas estas personas nacidas en otros países, antes de estar empleadas en inserción, se encontraban en desempleo, y merced al contrato de trabajo, se les proporciona una remuneración y una oportunidad para desarrollarse, así como para mantener su situación administrativa regularizada.

Los responsables de las empresas de inserción son conscientes de las dificultades a las que se enfrentan los inmigrantes extranjeros como colectivo en el que están repercutiendo con especial crudeza los efectos de la crisis. Como relata un mando responsable de una de las empresas de inserción vascas:

“En el caso de la gente inmigrante, normalmente migra porque en su país no hay trabajo. Estar fuera de su lugar, fuera de su familia, crea una serie de problemas [...]. Lo primero [...] es intentar estabilizar su vida de manera personal. Una vez que esa parte del proceso está hecha, entraría a la primera fase de un itinerario de inserción, de lo que sería el tema de habilidades sociales; cuando hablas de habilidades sociales, es desde cumplir un horario, hasta ser capaz de hablar con sus compañeros, no sólo por el tema del idioma, sino por tema de relaciones interpersonales. Este proceso puede durar, dependiendo de la persona, dos meses o puede durar tres años (12-EP-02).

En el perfil de estas personas de origen extranjero empleadas por estas empresas de la economía social y solidaria, destaca que son tanto hombres como mujeres, repartidos al $50 \%$, de una gran diversidad de nacionalidades, pero principalmente procedentes de países de Latinoamérica (48\%) -Bolivia, Colombia, Ecuador son los países con mayores porcentajes-, así como de países africanos (44\%) -Marruecos, Senegal, Argelia, en mayor medida-, aunque también algunos proceden de países asiáticos, como Nepal, Pakistán o Filipinas. Su mayor porcentaje se encuentra en el tramo de edad de entre los 25 y 34 años (43\%), y en su mayoría permanecen solteros (50\%), aunque solamente un $30 \%$ declara no tener hijos a su cargo, e incluso un $17 \%$ manifiesta tener 30 más hijos. Además, únicamente 1 de cada 3 declara no haber sido perceptor de la renta de garantía de ingresos (33\%), teniendo regularizada cerca de la totalidad su situación administrativa y contando con unos niveles de formación medios, primordialmente de educación secundaria (41\%).

Las empresas de inserción vascas han apostado por su integración y normalización en los heterogéneos sectores de actividad económica donde actúan, que van desde los servicios de limpieza, la mecánica y el reciclaje, hasta la restauración y los servicios industriales auxiliares. Se ha ido avanzando en el tratamiento dado a la cuestión migratoria presente en sus plantillas, integrándola de manera natural en los diferentes procesos. Como reconoce uno de los mandos entrevistados:

El tema de la inmigración [...] se ha considerado como algo transversal. [...] Se consideró que [las personas inmigrantes] eran igual que las autóctonas y que, por lo tanto, entraban en todos los servicios como el resto de las personas de aquí (EP-10).

Así, el tratamiento a las personas inmigrantes internacionales en inserción se considera semejante al de las personas autóctonas, al margen de cierto refuerzo de su limitación con el idioma, en el caso de requerirlo - una cuarta parte del conjunto analizado manifestó tener un domino básico o hablar con dificultad el castellano (25\%)-. El $80 \%$ ha recibido algún tipo de formación o preparación para desempeñar su trabajo en la empresa de inserción, tanto en habilidades sociales ( $95 \%$ ) como laborales, y nueve de cada diez ( $91 \%$ ) consideran que esta preparación les ha servido para mejorar en sus competencias sociolaborales. En este sentido, los trabajadores 
en inserción van rotando, durante su itinerario de acompañamiento, por diferentes actividades laborales para ir adquiriendo las competencias y destrezas necesarias para la consecución de la meta de las empresas de inserción, que no es otra que la de servir de puente para que sus empleados en inserción puedan acceder al mercado normalizado, bien a través de la contratación por cuenta ajena, bien por cuenta propia. En palabras de una de las personas inmigrantes:

Ahora mismo soy polivalente. Puedo estar en la camioneta, en el camión, en la tienda o en textil. En todo, en general. [...]. Cuando entré, empecé [...] y poco a poco fui pasando por diferentes tareas (El-03).

Entre las personas extranjeras en puestos de inserción, el $41 \%$ declara estar completamente satisfecho con su trabajo en la empresa. Incluimos una cita de la entrevista con una de ellas, para poner de manifiesto su sentimiento positivo hacia la labor desarrollada por las empresas de inserción en las que desempeñan su trabajo, de cara a la mejora de su grado de integración tanto social y laboral, cita donde se refleja la especial importancia que dan a su paso por aquéllas:

\section{Yo creo que hasta ahora me han ayudado mucho y} todavía nos siguen apoyando también, sobre los estudios y [a] aprender, para que algún día, cuando nos marchemos de aquí, tendremos una buena experiencia para mejorar y que nos cojan (El-18).

En cuanto al colectivo femenino, cabe indicar que prácticamente la totalidad de empresas de inserción vascas cuentan con mujeres en sus plantillas, y otra característica reseñable es la notable feminización de las plantillas de las empresas de inserción, las cuales, salvo excepciones relacionadas con el sector de producción -por ejemplo, la construcción-, tienen alta presencia de mujeres trabajadoras tanto en plazas de inserción como de no inserción. En 2012, el $56 \%$ de las 641 personas empleadas en puestos de inserción eran mujeres. Además, es de interés destacar que la mayoría, aproximadamente 6 de cada 10 de las mujeres empleadas en las empresas de inserción vascas lo estaba en un puesto de inserción $(60,5 \%)$, con un perfil muy plural. Como recogimos en una de las entrevistas con uno de los mandos sobre las mujeres en procesos de inserción:

[...] es mayoritariamente trabajo con mujeres. Yo creo que en este momento son todas mujeres. Mujeres con cargas familiares, monoparentales, inmigrantes, mujeres con tema de salud mental (09-TA-04).

En relación con las características sociodemográficas de estas mujeres, sus rasgos característicos corresponden a una mujer autóctona, no tan joven -prácticamente 3 de cada 10 tienen entre los 35 y los 44 años de edad-, que no vive en pareja (70\%), bien por estar soltera o por encontrarse separada 0 divorciada, y con cargas familiares, dado que solamente un $11 \%$ declara no tener descendencia, según los datos primarios de nuestra investigación. En cuanto a su nivel formativo, son mayoría las féminas con un grado de instrucción secundario (42\%), de manera similar a lo que ocurría entre las personas de origen extranjero.

Al referirse a la experiencia de trabajo con mujeres, los técnicos de acompañamiento de las empresas de inserción reconocen, por una parte, el mayor riesgo de vulnerabilidad de ciertas mujeres y, por otra, cómo el perfil de la mujer empleada con contrato en inserción parte de un nivel muy bajo de autoestima. En palabras textuales de dos de estos técnicos:

Yo entiendo que el ser mujer, y además en riesgo de exclusión social, es como una doble característica de exclusión. Nosotros intentamos contar con el máximo posible de mujeres (05-TA-02).

[...] las mujeres que vienen sí que tienen un desajuste con la autoestima y [abordarlo] es un trabajo que, o bien lo hacen las psicólogas que tenemos en el centro o bien [lo hacemos] con las citas de acompañamiento (26-TA-11).

Como relata sobre su experiencia vital una de las mujeres que ha participado en el trabajo de campo realizado:

Me casé joven, con 23 años, y enseguida empecé a tener niños (tengo tres niñas), con lo cual he estado muchos años ocupándome de mi hogar y de las niñas. Así que no he trabajado durante mucho tiempo por ocuparme de la familia. Al divorciarme, me encontré en la situación de que tenía que hacerme cargo yo sola de mi casa y de mis tres hijas. Y por eso empecé a buscar trabajo y empecé a encontrar algún empuje laboral. Es difícil, en este paro tan largo de tiempo como son catorce años, reintegrarte a la vida laboral. Cuando te has ocupado siempre de tu casa. Y el reciclarte, también, porque la tecnología avanza, todo avanza y tú te quedas un poco obsoleta. Así que, con 36 años, es difícil empezar a trabajar, sobre todo con cargas familiares y siendo mujer, es bastante difícil (EM-04).

Ciertamente la manera de compatibilizar horarios es una variable muy importante por el tipo de colectivo femenino que participa en los procesos de inserción, ya que, como señalamos en líneas anteriores, aproximadamente 7 de cada 10 de estas mujeres no viven en pareja y 9 de cada 10 reconocen tener descendencia. Como señala uno de gerentes de las empresas de inserción vascas:

Tenemos algunas madres solteras o solas ahora mismo, que eso ya genera problemas con los horarios. Eso lo tenemos en cuenta y, en la medida de lo posible, lo ajustamos. Siempre digo en la medida de lo posible, porque lo primero que hacemos aquí es trabajar (GE-01). 
Asimismo, el cierto grado de vulnerabilidad de estas mujeres se refleja a través del dato que indica que el $71 \%$ de las mujeres empleadas eran perceptoras de la renta de garantía de ingresos antes de su ingreso en la empresa de inserción, en la cual, prácticamente 2 de cada 5 ( $42 \%$ ) entraron a través de los servicios públicos de empleo:

Antes estaba en el paro. Llevaba así bastante tiempo, porque bueno, igual me llamaban para una sustitución de dos meses o tres meses. $Y$ luego volvía al paro, y así (EM-01).

Un $77 \%$ dice haber recibido formación para el desempeño de su trabajo una vez contratada, pese a que un $70 \%$ de las mujeres manifiestan haber tenido una experiencia previa de trabajo partiendo de una situación de desempleo cuando entraron a formar parte de la plantilla de la empresa de inserción. Una de las mujeres entrevistadas señala:

Bueno, siempre trabajando. He hecho de todo, he estado cosiendo redes, he estado en fábrica de conserva, he estado cuidando niños, he estado limpiando casas, he estado en dos empresas de metal, y luego aquí. No pude estudiar nada, hasta los 8 años, lo básico, hasta dividir y ya está. Antes de llegar aquí, he estado desempleada dos años casi, bueno, más de dos años, sí. Ese tiempo estuve cobrando la RGI [renta de garantía de ingresos] (EM-06).

En cuanto al grado de satisfacción que declaran las mujeres empleadas en inserción, el $46 \%$ declaran estar totalmente satisfechas del trabajo en la empresa, y el $87 \%$ manifiestan estar plena o muy altamente satisfechas del trato recibido en la empresa. En el discurso de una de las mujeres entrevistadas recogimos el siguiente comentario:

[...] al ser un programa de reinserción, la verdad [es] que tienes mucha ayuda en cuanto [a lo] laboral, pero también humana, porque claro, siempre vienes con algún problema añadido. Te quiero decir, en mi caso, tengo mis niñas, y son bastante flexibles. También tienen un acompañamiento humano contigo, el saber en cada momento cómo estás, por lo que estás pasando, cómo estás tú anímicamente. Porque claro, imagino que cuando uno está bien anímicamente, se expresa en el trabajo del día a día, bueno para ambas partes... [Respecto al] acompañamiento laboral, [...] te ayudan a familiarizarte con tu herramienta de trabajo y luego también a organizar tu currículo, a ver cómo lo puedes actualizar, cómo lo puedes mejorar. Siempre que hay ferias de empleo, dan unos listados y te comentan, ¿no?, “mira, existen estas ofertas de empleos, si te apetece apuntarte". Porque claro, estas empresas tienen caducidad (EM-04).

En definitiva, los propios sujetos reconocen la labor de acompañamiento en puestos de inserción orquestada para la integración sociolaboral por este tipo de entidades sociales donde la propia persona es la protagonista. De ahí que suponga una palanca de activación y dinamismo, de lucha por reducir la exclusión con resultados positivos en el plano personal y en el conjunto de la sociedad.

\section{Consideraciones finales}

De las preguntas planteadas en esta investigación, que se propuso comprender y explicar cómo se enfrenta y se resuelve la integración social a través del empleo del colectivo más vulnerable de inmigrantes y de mujeres en la economía social y solidaria en el territorio vasco, se ha podido obtener un mapa general de la situación, que escenifica y analiza dos variables centrales en los puestos de inserción en Euskadi: el origen y el género. En este sentido, se ha podido constatar que son las personas autóctonas las que en su mayoría trabajan en puestos de inserción. Sin embargo, las personas de origen inmigrante han aumentado su presencia hasta suponer poco más del $42 \%$ del total de los empleos de inserción en estas iniciativas empresariales vascas, y están presentes asimismo en prácticamente la totalidad de las empresas de inserción vascas. Por su parte, el colectivo femenino tiene un peso mayoritario y significativo entre las personas trabajadoras en inserción (56\%), estando también presente en cerca de la generalidad de estos dispositivos de la economía social y solidaria vasca. Es decir, que de 5 trabajadores en puestos de inserción, aproximadamente 3 son mujeres y 2 son de origen extranjero, con perfiles diferentes, pero coincidentes primordialmente en el nivel formativo de secundaria y, a pesar de estar mayoritariamente solteros o separados/divorciados, en tener cargas familiares.

Consiguientemente, las empresas de inserción están demostrando ser un dispositivo lícito y favorecedor de cara a la inserción social y la activación laboral de estos dos colectivos desfavorecidos residentes en territorio vasco, al ofrecerles oportunidades de mejora, gracias a su apertura a todos y a una gestión integral del fenómeno multicausal de la vulnerabilidad social. Son empresas sociales que fomentan un aprendizaje activo y útil por medio de itinerarios significativos personalizados, construidos adaptándose a las necesidades de cada persona en inserción con acciones que reciben un seguimiento individualizado. Parten de proyectos integradores y motivantes para las personas, desde algo tan concreto como es la realización de una actividad productiva y una experiencia de trabajo real focalizada en mejorar sus niveles de empleabilidad.

La cierta madurez de las empresas de inserción dentro de los agentes existentes en la economía social y solidaria vasca permite vislumbrar que este tipo de empresas y sus entidades promotoras están instituyéndose en actores sociales claves para la integración sociolaboral de las personas de origen extranjero y de las mujeres más desfavorecidas, a través de su filosofía y metodología de actuación 
proactiva y respetuosa con las disparidades características de cada sujeto en inserción. Las empresas de inserción vascas han apostado por la integración y normalización de estos colectivos, enfrentándose a la creciente desigualdad y pluralidad vivida en CAPV desde el arranque del siglo XXI, marcada especialmente por la llegada de una fuerte inyección de personas trabajadoras procedentes de muy diferentes lugares del planeta, y por las repercusiones de una crisis sistémica.

A pesar de que las empresas de la economía social y solidaria forman parte de nuestro entorno próximo y son una realidad cada vez más importante y reconocida, existe una destacada ignorancia en torno a sus principios y su significativa contribución social. De hecho, siempre teniendo como horizonte de su trabajo que las empresas de inserción se deben a la inserción sociolaboral de sus trabajadores en inserción, amén del desarrollo de su actividad comercial, nos surgen dudas sobre la visibilidad real, en la sociedad en general, del trabajo profesional que desarrollan estas empresas para lograr la colaboración con distintos agentes sociales, tanto públicos como privados. No se puede obviar que los agentes de la economía social y solidaria mantienen valores de interés general que deben ir adaptándose a las condiciones cambiantes, pero siempre con el objetivo de aplicar prácticas económicas alternativas, enraizadas en la fertilidad de la tradición vasca, desde experiencias inclusivas y desde el paradigma de situar la actividad económica en medio de las necesidades humanas, al primar a las personas y al fin social sobre el capital, y al promocionar su compromiso con el desarrollo local, la paridad y la cohesión social. Estas cuestiones forman parte del conjunto de necesidades y preocupaciones vigentes en sociedades democráticas y avanzadas, como lo es la sociedad vasca.

Los verdaderos retos de futuro de estas empresas pasan por mantenerse dentro de un difícil contexto donde imperan los recortes y las dilaciones -que también les afectan-, y por mejorar su visibilidad social. De hecho, los datos de nuestro estudio permiten afirmar que en la actualidad el sector de la economía social y solidaria es un significativo motor que contribuye a la integración social a través del empleo del colectivo en mayor desventaja en el contexto vasco, donde deben contribuir a definir y marcar unas pautas que alumbren la aplicación positiva de medidas para lograr la convivencia óptima. Confiemos en que los resultados expuestos aporten algunas informaciones útiles para el logro de la cohesión social, de cara a la adaptación de la sociedad al contexto fracturado y plural imperante, desde el respeto y puesta en valor de las diferencias, y desde la eliminación de barreras que impiden la participación plena de todos los individuos.

De cara al futuro, puede ser interesante profundizar en torno a la idea de hasta qué punto pueden 'exportarse' las prácticas desarrolladas por este tipo de empresas a otros contextos. Asimismo, convendría replantearse los discursos y modelos existentes, reflexionando con serenidad para ver si cumplen adecuadamente con su labor de inserción e integración cuando la metodología que aplican se malogra para ciertos empleados en inserción que abandonan el proceso o no llegan a integrarse después en el mercado laboral ordinario. 
ARANGO, J. (2012): "Nubes en un cielo aún sereno", El País, 22-10-12 [rhttp://sociedad. elpais.com/sociedad/2012/10/21/ vidayartes/1350843470_714712.html/].

ARETXABALA, M. E. (2012): “La labor de las empresas de inserción como puente de inclusión sociolaboral para los inmigrantes internacionales más vulnerables", en ACILLONA, M. (ed.), Marcos interpretativos de la realidad social contemporánea, Bilbao, Universidad de Deusto, págs. 163-178.

ARETXABALA, M. E.; y SETIÉN, M. L. (2014): El reto de las diversidad para las empresas de inserción vascas. El empleo de inmigrantes y mujeres, Bilbao, Publicaciones de la Universidad de Deusto.

COQUE, J.; y PÉREZ FERNÁNDEZ, E. (eds.) (2000): Manual de creación y gestión de empresas de inserción social, Oviedo, Servicio de Publicaciones de la Universidad de Oviedo.

CÓRDOBA, A.; y MARTÍNEZ MORALES, I. (coords.) (2011): Trabajo, empleabilidad y vulnerabilidad social: condicionantes y potencionalidades de la integración a través de las empresas de inserción social, Valencia, Universidad de Valencia.

CRUZ ROJA (2011): Guía para la orientación laboral de colectivos vulnerables, Madrid, Cruz Roja.

DEFOURNY, J.; y NYSSENS, M. (2013): El enfoque EMES de empresa social desde una perspectiva comparada, serie Working Papers, $\mathrm{n}$-13/01, Bruselas, EMES European Research Network.

ESPAÑA (2011): “Ley 5/2011, de 29 de marzo, de Economía Social”, Boletín Oficial del Estado, $\mathrm{n}-76,30-3$ 11, págs. 33.023-33.033 [<http://www.boe.es/ buscar/doc.php?id=BOE-A-2011-5708〉].
- (2010): "Real Decreto 49/2010, de 22 de enero, por el que se crea el Registro Administrativo de Empresas de Inserción del Ministerio de Trabajo e Inmigración", Boletín Oficial del Estado, 꿀29, 3-2-10, págs. 9.681-9.683 [rhttp://www.boe. es/buscar/doc.php?id=BOE-A-2010-1660〉].

- (2009): “Ley 27/2009, de Medidas Urgentes para el Mantenimiento y el Fomento del Empleo y la Protección de las Personas Desempleadas", Boletín Oficial del Estado, nํㅜ 315, 31-12-09, págs. 112.018-112.035 [<http://www.boe.es/ buscar/doc.php?id=BOE-A-2009-21160〉].

- (2007): “Ley 44/2007, de 13 de diciembre, para la Regulación del Régimen de las Empresas de Inserción”, Boletín Oficial del Estado, no 299 , 14-12-07, págs. 51.331-51.339 [<http://www.boe. es/buscar/doc.php?id=BOE-A-2007-21492〉].

EUROSTAT (2012): “At risk of poverty or social exclusion in the EU27", Eurostat Newsrelease, no 21/2012, 8-2-12.

CÁRITAS ESPAÑOLA (2013): Empobrecimiento y desigualdad social. VIII Informe del Observatorio de la Realidad Social, Cáritas Española [rhttp:// www.caritas.es/publicaciones_download. aspx?!d=4706〉].

GIL, M. E.; y RAMOS, N. (2013): "Las empresas de inserción en la economía social y solidaria: perspectivas y propuestas desde FAEDEI", Cuadernos de Trabajo Social, vol. 26, nํㅜ 1, págs. 43-53.

GIZATEA-ASOCIACIÓN DE EMPRESAS DE INSERCIÓN DEL PAÍS VASCO (2013a): Las empresas de inserción en el País Vasco: memoria social 2011, Bilbao, Gizatea-Asociación de Empresas de Inserción del País Vasco. 
- (2013b): Informe diagnóstico. Impacto de la crisis sobre las empresas de inserción del País Vasco, Bilbao, Gizatea-Asociación de Empresas de Inserción del País Vasco; Eusko JaurlaritzaGobierno Vasco.

- (2012): Las empresas de inserción en el País Vasco: memoria social 2011, Bilbao, Gizatea-Asociación de Empresas de Inserción del País Vasco.

- (2010): Las empresas de inserción en el País Vasco: memoria social 2009, Bilbao, GizateaAsociación de Empresas de Inserción del País Vasco.

GOBIERNO VASCO (2012a): Encuesta de Pobreza y Desigualdades Sociales, Vitoria-Gasteiz, Eusko Jaurlaritza-Gobierno Vasco.

- (2012b): III Plan Vasco de Inclusión Activa 2012-2016, Vitoria-Gasteiz, Eusko Jaurlaritza-Gobierno Vasco.

IKUSPEGI-OBSERVATORIO VASCO DE INMIGRACIÓN (2015): Panorámica de la Inmigración, nํㅡ 57 [<http:// www.ikuspegi-inmigracion.net/ documentos/ panoramicas/es/pan57cas.pdf)].

INE (2013): Encuesta de Población Activa (EPA). Tercer trimestre de 2013, serie Notas de Prensa, Instituto Nacional de Estadística, 24-10-13 [khttp://www.ine.es/daco/daco42/dac04211/ epa0313.pdf>].

LAPARRA, M.; y PÉREZ ERANSUS, B. (coords.) (2012): Crisis y fractura social en Europa. Causas y efectos en España, Barcelona, Obra Social La Caixa.

MARCUELLO, C. et al. (2008): Informe sobre las empresas de inserción en España, serie Informes, $\mathrm{n}^{\circ} \mathbf{4}$, Valencia, CIRIEC-España.
OBSERVATORIO VASCO DE ECONOMÍA SOCIAL (2014): Informe de situación de la economía social vasca. Año 2013 [khttp://www.oves-geeb. com/uploads/files/es/cientifico-academica/ Informe_Economia_Social_vasca_ noviembre_2014.pdf $)$.

PAÍS VASCO (2008): “Decreto 182/2008, de 11 de noviembre, por el que se Regula la Calificación de Empresas de Inserción, Se Establece el Procedimiento de Acceso a las Mismas y su Registro", Boletín Oficial del País Vasco, № 225, 24-11-2008 [<http://www.euskadi.net/bopv2/ datos/2008/11/0806515a.pdf〉].

PESTOFF, V. (1998; 2005): Beyond the Market and State. Civil Democracy and Social Enterprises in a Welfare Society, Aldershot; Brookfield, Ashgate.

REAS-EUSKADI (2011): Carta de la Economía Solidaria [rhttp://www.economiasolidaria.org/carta_ solidaria〉].

ROCHA, F.; y ARAGÓN, J. (2012): La crisis económica y sus efectos sobre el empleo en España, Madrid, Fundación Primero de Mayo.

SALINAS, F.; y HERRANZ DE LA CASA, J. M. (dirs.) (2004): La economía social como puerta de integración sociolaboral de los inmigrantes, Ávila, Publicaciones Universidad Católica de Ávila.

URRA, M. (2010): “El papel de la economía social en los regímenes del bienestar", Revista Miscelánea Comillas, vol. 68, nํㅜ133, págs. 791-816.

VECIANA, P. (2007): Las empresas de inserción en España, Barcelona, Fundación Un Sol Món. 